\title{
DEVELOPMENT OF THE MEASURES FOR PREVENTION AND CORRECTION OF THE NERVOUS SYSTEM DISORDERS RELATED TO STRESS IN THE UNDERGROUND TRAIN DRIVERS
}

Dumka I.V., Tkachyshyn V.S., Tkachyshyna N.Yu.

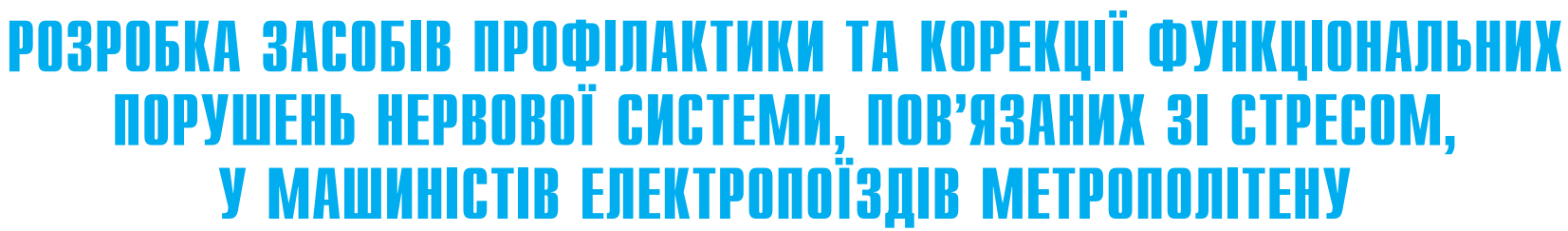

1 ДУМКА І.В., 2 ТКАЧИШИН В.С., 3 ТКАЧИШИНА Н.Ю.

1 ДП «Український медичний центр безпеки дорожнього руху та інформаційних технологій МОЗ України», м. Київ

2 Національний медичний університет

ім. О.О Богомольця, м. Київ

3 ДЗ «Дорожня клінічна лікарня № 2 ст. Київ» ДТГО ПЗЗ»

Удк $613.62: 656.071 .2: 616.8$

Ключові слова: машиністи електропоїздів метрополітену, несприятливі виробничі

чинники, стресостійкість, загальносоматична патологія. тресовий фактор $€$ одним з провідних несприятливих виробничих чинників, що діють на машиністів електропоїздів метрополітену (МЕП) під час роботи, може проявлятися насамперед розвитком вегетативної дисфункції.

Метою дослідження було вивчення стресостійкості та рівня тривожності серед МЕП і працівників інженерної ланки, а також розробка схеми лікування вегетативної дисфункції у МЕП.

Матеріали і методи. Показанням для призначення комплексної терапії обстеженим МЕП було виявлення у них гострої реакції на стрес (F 43.0) з розладами вегетативної (автономної) нервової системи. За даними критеріями було відібрано 26 МЕП. Хворі проходили амбулаторне лікування у ДЗ «Вузлова поліклініка станції Київ» Державного територіального об'єднання «Південно-Західна залізниця». Курс лікування становив $(26,08 \pm 0,94)$ днів. Вік пацієнтів - $(35,17 \pm 1,59)$ років. Усі МЕП - чоловіки. У якості рандомізованої за своїми основними параметрами (статтю і віком) контрольної групи
РАЗРАБОТКА МЕР ПРОФИЛАКТИКИ И КОРРЕКЦИИ НАРУШЕНИЙ НЕРВНОЙ СИСТЕМЫ, СВЯЗАННЫХ СО СТРЕССОМ, У МАШИНИСТОВ ЭЛЕКТРОПОЕЗДОВ МЕТРОПОЛИТЕНА

1 Думка И.В., 2 Ткачишин В.С., 3 Ткачишина Н.Ю. 1 ГП «Украинский медицинский центр безопасности дорожного движения и информационных технологий Минздрава Украины», г. Киев

2 Национальный медицинский университет

им. А.А. Богомольца, г. Киев

3 ГУ «Дорожная клиническая больница № 2 ст. Киев" ДТГО ЮЗЖД»

Целью исследования было изучение стрессоустойчивости и уровня тревожности у машинистов электропоездов метрополитена (МЭП) и разработка схемы лечения вегетативной дисфункции.

Материалы и методы. Обследовано две группы лиц: 26 МЭП (основная группа), 26 работников инженерно-технического звена (контрольная группа). Все обследуемые лица основной и контрольной групп - мужчины. Для изучения стрессоустойчивости и уровня тревожности использовался тест Спилбергера.

Результаты и их обсуждение. Анализ результатов исследований показал, что у большинства МЭП $(88,5 \%)$ отмечается средний и высокий уровни тревожности, в отличие от работников инженерного звена (23, 19\%). Имеет место достоверная разница $(p<0,05)$ между аналогичными значениями в обеих группах. Это свидетельствует о том, что большинство машинистов страдают от постоянного воздействия стрессового фактора на рабочих местах, учитывая специфику их работы, что приводит к снижению стрессоустойчивости и повышению уровня ситуативной тревожности среди МЭП. Такой тенденции не наблюдается в контрольной группе, что свидетельствует о том, что их труд не связан с чрезмерным воздействием стрессового фактора на нервную систему работников инженер- ного звена. По результатам теста Спилбергера можно отметить, что МЭП с низкой стрессоустойчивостью и высоким уровнем тревожности могут быть подвержены неуравновешенности, невнимательности, низкому уровню самоконтроля, что опасно для их профессии, учитывая необходимость обеспечения безопасного движения поездов. Согласно собранному анамнезу у 26 МЭП (100\%) вышеуказанные патологические состояния возникли в результате стрессовых ситуаций (в анамнезе - наезд на человека с летальным исходом). С целью коррекции выявленных нарушений была предложена схема лечения, основной целью которой является восстановление нормального функционирования нервной системы в целом и исчезновения ее соматоформных проявлений. Так, в начале лечения лица с депрессивным синдромом составляли $(84,61 \pm 7,07) \%$, в конце $(3,84 \pm 3,77) \%$, что достоверно меньше $(p<0,01)$. В начале лечения лица с астеновегетативным синдромом составляли $(92,30 \pm 5,22) \%$, в конце $(7,69 \pm 5,22) \%$, что достоверно меньше $(p<0,01)$. Выводы. В ходе опроса МЭП и выяснения психофизиологических факторов риска вегетативной дисфункции было установлено, что у большинства МЭП $(88,5 \%)$ отмечается средний и высокий уровни тревожности, в отличие от работников инженерной звена (23,19\%). Разница значений имеет достоверный $(p<0,05)$ характер. Разработанную схему коррекции патологических изменений нервной системы у МЭП, возникших в результате стресса, можно эффективно использовать для возобновления функционирования работы нервной системы, о чем свидетельствует положительная динамика состояния здоровья машинистов до и после лечения.

Ключевые слова: машинисты электропоездов метрополитена, неблагоприятные производственные факторы, стрессоустойчивость, общесоматическая патология. 
було взято працівників інженерної ланки у кількості 26 осіб, робота яких не пов'язана з впливом шкідливих факторів виробничого середовища на їхній організм.

Для вивчення стресостійкості та рівня тривожності серед МЕП і працівників інженерної ланки проведено психологічний тест Спілбергера, який належить до числа методик, що визначають психологічний рівень тривожності та стресостійкості. Вивчався показник ситуативної тривожності (РТ), який визначає тривожність як стан, що пов'язаний з ситуацією, в якій перебуває обстежений. Обстежуваному пропонується уважно прочитати кожне 3 наведених речень тесту і закреслити відповідну цифру залежно від того, як він почувається на даний момент.

Показник РТ розраховувався за формулою:

$P T=\sum 1-\sum 2+50$

де $\sum 1$ - сума закреслених цифр за пунктами шкали 3, 4, 6, 7, 9, 12, 13, 14, 17, 18;

$\sum 2$ - сума закреслених цифр за пунктами шкали 1, 2, 5, 8, 10, 11, 15, 16, 19, 20.

Якщо показник РТ не перевищує 30, то, відповідно, обстежений не відчуває особливої тривоги, тобто у нього на даний момент низький рівень тривожності. Якщо сума визначається в інтервалі 31-45, то це означає середній рівень тривожності. Якщо 46 і більше - тривожність високого рівня.

Особиста тривожність відносно стабільна і не пов'язана з ситуацією, оскільки є властивістю особистості. Тому даний показник під час досліджень не визначався.

Результати та їх обговорення. Результати тесту Спілбергера МЕП та працівників інженерної ланки представлено у таблиці 1 .

Проаналізувавши результати досліджень (табл. 1), можна зробити висновок, що у більшості МЕП $(88,5 \%)$ відзначається середній та високий рівні тривожності на відміну від працівників інженерної ланки $(23,19 \%)$. Зважаючи на те, що має місце достовірна різниця $(\mathrm{p}<0,05)$ між аналогічними значеннями в обох групах, можна говорити, що більшість машиністів страждає через постійну дію стресового

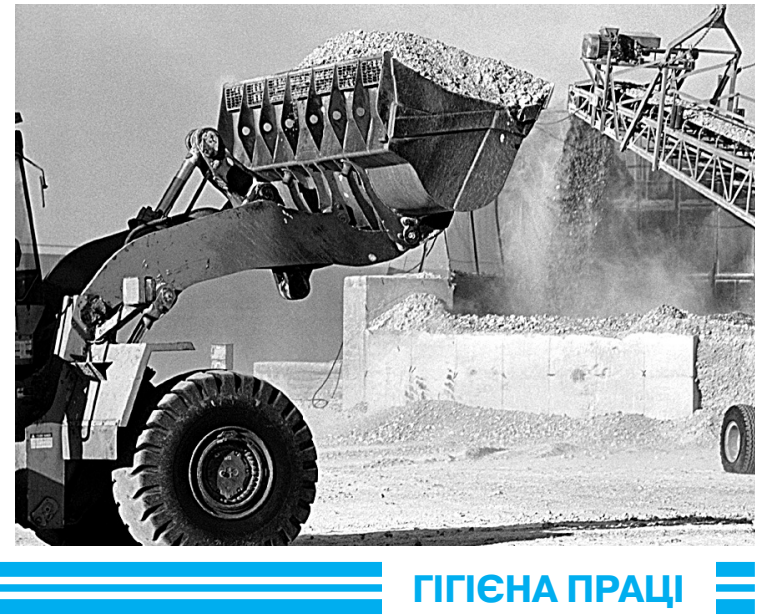

фактора на робочих місцях, враховуючи специфіку їхньої роботи, що призводить до зниження стресостійкості та підвищення рівня ситуативної тривожності серед МЕП. Така тенденція відсутня у контрольній групі, що свідчить про те, що їхня праця не пов'язана з надмірною дією стресового фактора на нервову систему працівників інженерної ланки. За результатами тесту Спілбергера також можна відзначити, що МЕП, які мають низьку стресостійкість та високий рівень тривожності, можуть бути схильними до неврівноваженості, неуважності, низького рівня самоконтролю, що $€$ небезпечним для їхньої професії, зважаючи на забезпечення безпечного руху поїздів. Тому необхідно з такими машиністами проводити індивідуальні психологічні тренінги за участі лікаря

психотерапевта. А під час працевлаштування протипоказаннями за психофізіологічними показниками мають бути неврівноваженість, слабка нервова система, низька стресостійкість, неуважність, низький рівень самоконтролю. Рівень тривожності за результатом психологічного тесту Спілбергера має бути не $>45 \%$.

Основною метою лікування цієї категорії осіб є відновлення нормального функціонування нервової системи загалом та зникнення їі соматоформних проявів. Призначена базисна терапія корегувалась в окремих випадках індивідуально з урахуванням супутніх захворювань деяких пацієнтів.

Основні принципи лікування:

口 нормалізація процесів нейрогуморальної регуляції механізмів адаптації, пов'язаних зі стресом, усунення

Таблиця 1

\section{Поширеність стресостійкості та рівня тривожності} серед обстежених груп

\begin{tabular}{|c|c|c|c|c|}
\hline $\begin{array}{c}\text { Значення } \\
\text { показника } \\
\text { РТ }\end{array}$ & $\begin{array}{c}\text { Основна } \\
\text { група (n=26), } \\
\text { кількість } \\
\text { працівників }\end{array}$ & $\begin{array}{c}\text { \% спів- } \\
\text { відношення, } \\
(\mathrm{M} \pm \mathrm{m})\end{array}$ & $\begin{array}{c}\text { Контрольна } \\
\text { група (n=26), } \\
\text { кількість } \\
\text { працівників }\end{array}$ & $\begin{array}{c}\text { \% спів- } \\
\text { відношення, } \\
(\mathrm{M} \pm \mathrm{m})\end{array}$ \\
\hline До 30 & 3 & $11,50 \pm 6,39^{*}$ & $20(76,9)$ & $76,90 \pm 8,43$ \\
\hline $30-45$ & 13 & $50,00 \pm 10,00^{\star}$ & $4(15,5)$ & $15,50 \pm 7,22$ \\
\hline$>45$ & 10 & $38,50 \pm 9,73^{*}$ & $2(7,6)$ & $7,69 \pm 5,33$ \\
\hline
\end{tabular}

Примітка: * - різниця достовірна між аналогічними показниками обстежених груп $(p<0,05)$.

Таблиця 2

Вплив лікування на динаміку скарг МЕП з порушеннями функціонування нервової системи $(n=26)$

\begin{tabular}{|c|c|c|c|c|c|c|}
\hline \multirow{3}{*}{ Синдром } & \multicolumn{4}{|c|}{ Кількість осіб зі скаргами } & \multirow{3}{*}{$\begin{array}{l}\text { t-критерій } \\
\text { Ст'юдента }\end{array}$} & \multirow{3}{*}{$\begin{array}{c}\text { Рівень } \\
\text { значи- } \\
\text { мості (P) }\end{array}$} \\
\hline & \multicolumn{2}{|c|}{ до корекції } & \multicolumn{2}{|c|}{ після корекції } & & \\
\hline & Абс. & $\mathrm{M} \pm \mathrm{m}, \%$ & Абс. & $\mathrm{M} \pm \mathrm{m}, \%$ & & \\
\hline $\begin{array}{l}\text { Депресивний } \\
\text { синдром }\end{array}$ & 22 & $84,61 \pm 7,07$ & 1 & $3,84 \pm 3,77^{*}$ & 10,07 & $\mathrm{p}<0,01$ \\
\hline $\begin{array}{l}\text { Астеновеге- } \\
\text { тативний } \\
\text { синдром }\end{array}$ & 24 & $92,30 \pm 5,22$ & 2 & $7,69 \pm 5,22^{*}$ & 11,44 & $p<0,01$ \\
\hline $\begin{array}{l}\text { Скарги } \\
\text { відсутні }\end{array}$ & 0 & 0 & 23 & $88,46 \pm 6,26$ & & \\
\hline
\end{tabular}


гострої реакції на стрес (F 43.0);

$\square$ усунення астено-вегетативних порушень (G 90), фобій, тривог та спогадів про стресову ситуацію, розладів сну, депресії (F40 - F48).

Для корекції виявлених порушень функціонування нервової системи було розроблено схему лікування МЕП:

$\square$ режим амбулаторний;

$\square$ нообут (фенібут) 25 мг, по 1 таблетці 2 рази на день;

м мільгама (ціанокобаламід, піридоксин, тіамін) 2,0 мл, внутрішньом'язово 1 раз на день;

口 гліцисед (кислота амінооцтова) 100 мг, по 1 таблетці 3 рази на день;

口івортін (аргеніна гідрохлорид) 100 мл, по 25 мл 4 рази на день;

масаж комірцевої зони № 10 ;

гальванічний комірець за Щербаком № 7;

口 спелеотерапія тривалістю 1 година № 15.

Таку терапію можна вважати базисною, оскільки вона застосовувалася в усіх пролікованих МЕП. Призначені препарати спрямовані на корекцію патологічних змін уражених органів і систем відібраних для лікування МЕП [1-6]. Слід зазначити, що застосована схема лікування відповідає вимогам стандартів (протоколів лікування) медичної допомоги в Україні.

Висновки щодо ефективності лікування ґрунтувалися на позитивній динаміці клінічних результатів. До клінічних критеріїв ефективності лікування було віднесено

зникнення скарг у пацієнта;

$\square$ зникнення основних клінічних синдромів (астеновегетативного та депресивного);

$\square$ покращання загального

\section{Результати тесту Спілбергера до та після лікування}

\begin{tabular}{|c|c|c|c|c|}
\hline \multirow[b]{2}{*}{$\begin{array}{c}\text { Значення } \\
\text { показ- } \\
\text { ника РТ }\end{array}$} & \multicolumn{2}{|c|}{ До лікування } & \multicolumn{2}{|c|}{ Після лікування } \\
\hline & $\begin{array}{c}\text { Основна } \\
\text { група }(n=26), \\
\text { кількість пра- } \\
\text { цівників }\end{array}$ & $\begin{array}{c}\text { \% спів- } \\
\text { відношення, } \\
(\mathrm{M} \pm \mathrm{m})\end{array}$ & $\begin{array}{c}\text { Основна } \\
\text { група }(n=26), \\
\text { кількість пра- } \\
\text { цівників }\end{array}$ & $\begin{array}{c}\text { \% спів- } \\
\text { відношення, } \\
(\mathrm{M} \pm \mathrm{m})\end{array}$ \\
\hline До 30 & 3 & $11,50 \pm 6,39^{*}$ & 13 & $50,0 \pm 10,0$ \\
\hline $30-45$ & 13 & $50,00 \pm 10,00^{*}$ & 8 & $31,0 \pm 9,0$ \\
\hline$>45$ & 10 & $38,50 \pm 9,73^{\star}$ & 5 & $19,0 \pm 8,0$ \\
\hline
\end{tabular}

Примітка: * - різниця достовірна між аналогічними показниками обстежених груп $(p<0,05)$. ційна лабільність. Під кінець лікування скарги залишилися лише в 1 МЕП, що становить $(3,84 \pm 3,77) \%$. При порівнянні аналогічних показників на початку та наприкінці лікування спостерігаємо достовірну різницю $(p<0,01)$.

Виходячи 3 даних таблиці 2, на початку лікування астеновегетативні порушення спостерігали у $(92,30 \pm 5,22) \%$ пацієнтів даної підгрупи ПЛБ. Під час перебування у стаціонарі у хворих поступово зникали сонливість та загальна слабкість. Пацієнти стали почуватися більш бадьоро, зникла підвищена стомлюваність. Поступово зменшувалися перепади тиску та пульсу, зникав мігруючий головний біль. Наприкінці лікування скарги, що віднесені до групи астеновегетативних порушень, залишилися лише у 2 МЕП, що становить $(7,69 \pm$ $5,22) \%$. При порівнянні аналогічних показників на початку та наприкінці лікування спостерігається достовірна різниця $(p<0,01)$.

На початку лікування усі 26 МЕП відзначали депресивні та/або астеновегетативні порушення. Але наприкінці лікування скарги з боку порушення функціонування нервової системи були відсутніми вже у 23 хворих МЕП, що становить $(88,46 \pm 6,26) \%$. Дані аналогічні показники при порівнянні достовірно відрізняються між собою $(p<0,01)$.

У таблиці 3 представлено результати тесту Спілбергера до та після лікування, які підтверджують ефективність запропонованої схеми лікування та корекції виявлених порушень у МЕП.

\section{Висновки}

1. У ході опитування МЕП і з'ясування психофізіологічних факторів ризику вегетативної дисфункції було встановлено, що у більшості МЕП (88,5\%) відзначається середній та високий рівні тривожності, на відміну від працівників інженерної ланки (23,19\%). Різниця значень має достовірний характер $(p<0,05)$.

2. Розроблену схема корекції патологічних змін нервової системи у МЕП, що виникли під час гострої стресової ситуації, можна ефективно використовувати для віднов- 
DEVELOPMENT OF THE MEASURES FOR

PREVENTION AND CORRECTION OF THE NERVOUS SYSTEM DISORDERS RELATED TO STRESS IN THE UNDERGROUND TRAIN DRIVERS 1 Dumka I.V., 2 Tkachyshyn V.S., ${ }^{3}$ Tkachyshyna N.Yu. 1 "Ukrainian Medical Center for Traffic Safety and Information Technologies, MPH of Ukraine", Kyiv ${ }^{2}$ National O.O.Bohomolets Medical University, Kyiv 3 SI "Road Clinical Hospital No.2, Kyiv Station", NTBA SWRR"

Objective. We examined the stress resistance and the level of anxiety in the underground train drivers (UTD) and developed the scheme for treatment of the vegetative dysfunction.

Materials and methods. We examined two groups of individuals: 26 UTD (main group), 26 employees of the engineering unit (control group). All examined persons of main and control groups were men.

Spielberger test was used to study the stress resistance and anxiety level.

Results and discussion. Analysis of the study results showed that medium and high levels of anxiety were mentioned in the majority of UTD $(88.5 \%)$, in contrast to the personnel of engineering unit (23.19\%, respectively). There is a significant difference $(p<0.05)$ between similar values in both groups. This indicates that the majority of drivers suffer from the constant impact of stress factor in the workplaces, taking into account the specificity of their work, it leads to a decrease of stress resistance and increase of the level of situational anxiety among the UTD. There was no such a tendency in the control group, this indicated that their work is not connected with excessive impact of the stress factor on nervous system of the engineering personnel. By Spielberger test results, it may be noted that the UTD who have a low resistance to stress and a high level of anxiety, may be pruned to imbalance, lack of attention, low self-control, it is dangerous for their profession, taking into account that they provide safe movement of trains. According to the medical histories collected in 26 underground train drivers (100\%), above pathological states arose as a result of stress situations (in medical history it is the hitting on a person with a fatal outcome). For the correction of identified disorders a treatment scheme was proposed, its main task was a recovery of the normal functioning of nervous system in general and a disappearance of its somatoform symptoms.

Thus at the beginning of the treatment the percentage of the persons with a depressive syndrome was (84.61 $\pm 7.07) \%$. At the end of treatment this index made up $(3.84 \pm 3.77) \%$ that was significantly less $(p<0.01)$ in comparison with the same index at the beginning of the treatment. At the beginning of the treatment the percentage of the persons with the asthenovegetative syndrome made up $(92.30 \pm 5.22) \%$. At the end of treatment, this index was $(7.69 \pm 5.22) \%$ that was significantly less $(p<0.01)$ in comparison with the same index. Conclusions. In a survey of the UTD and identification of the psychophysiological vegetative dysfunction risk factors we established medium and high levels of anxiety in the majority of UTD (88.5\%), in contrast to the engineering personnel (23.19\%). The difference of values has a reliable $(p<0.05)$ character. Developed scheme for the correction of pathological changes of nervous system in the UTD, due to stresses, can be used effectively for the recovery of the functioning of nervous system, a positive dynamics of the state of health of the drivers before and after treatment indicates it.

Keywords: drivers of electric underground trains, unfavorable production factors, stress resistance, general-somatic pathology. лення та нормалізації роботи нервової системи у МЕП, про що свідчить позитивна динаміка стану МЕП до та після лікування. Так, на початку лікування особи з депресивним синдромом становили (84,61 \pm 7,07)\%, наприкінці лікування - $(3,84 \pm 3,77) \%$, що достовірно менше $(p<0,01)$. На початку лікування особи 3 астеновегетативним синдромом становили $(92,30 \pm$ $5,22) \%$, наприкінці - $(7,69 \pm$ $5,22) \%$, що достовірно менше $(p<0,01)$.

ЛІТЕРАТУРА

1. Стандарти медичної допомоги. Нормативнодирективні документи МО3 України. Режим доступу : http://www.moz.gov.ua/ua/portal/standards.html.

2. Вакуленко Л.О., Прилуцька Г.В., Вакуленко Д.В. Лікувальний масаж.

Тернопіль : Укрмедкнига, 2005. 448 c.

3. Учебно-методическое пособие по физиотерапии : для студентов IV курса лечебного факультета, а также для врачей-интернов и клинических ординаторов.
Волгоград, 2006. 172 с.

4. Фомичева М.Л. Щетинин А.Н., Шаропуто В.М. Физиолого-гигиенические основы первичной профилактики у сотрудников подземного железнодорожного транспорта Западной Сибири. Гигиена и санитария. 2003. № 4. C. 27-28.

5. Фомичева М.Л., Щетинин А.Н. Повышение физической работоспособности сотрудников подземного железнодорожного транспорта Западной Сибири. Гигиена и санитария. 2003. № 3 .

C. 27-28.

6. Дьякович М.П., Куренкова Г.В. Профессиональное здоровье работников, обслуживающих подземные железнодорожные магистрали Прибайкалья: функциональные резервы и риск донозологических состояний.

Тихоокеанский мед. журн. 2013. № 3. C. 64-68.

REFERENCES

1. Standarty medychno dopomohy. Normatyvno-dyrektyvni dokumenty MOZ Ukrainy [Standards for Health Care. Normative-Directive Documents of the MPHU]. URL :

http://www.moz.gov.ua/ua/portal/standards.html

(in Ukrainian)

2. Vakulenko L.O., Prylutska G.V. and Vakulenko D.V. Likuvalnyi masazh. Ternopil (Ukraine) : Ukrmedknyha ; 2005 : 448 p. (in Ukrainian).

3. Uchebno-metodicheskoe posobie po fizioterapii : dlia studentov IV kursa lechebnogo fakulteta, a takzhe dlia vrachei-internov I klinicheskikh ordinatorov [TeachingMethodical Manual on Physiotherapy: for the Fourth Year Students of the Medical Faculty and Doctor- and Clinical Interns].Volgograd; 2006 : 172 p. (in Russian).

4. Fomicheva M.L., Shchetinin A.N. and Sharoputo V.M. Gigiiena I sanitariia. 2003 ; 4 : 27-28 (in Russian).

5. Fomicheva M.L. and Shchetinin A.N. Gigiiena / sanitariia. 2003 ; 3 : 27-28 (in

Russian).

6. Diakovich M.P. and Kurenkova G.V. Tikhookeanskiy meditsinskiy zhurnal. 2013 ; 3 : 64-68 (in Russian).

Надійшла до редакції 14.03.2017 